\title{
The Impact of China's Capital Market Opening Up to the Domestic Stock Idiosyncratic Risk
}

\author{
Chenpeng $\mathrm{Du}^{1}$
}

\begin{abstract}
In this paper we studied impact of an exogenous event that represents China's capital market opening up policy: the "A-share inclusion in the MSCI index" for China's domestic Stock assets. By constructing the Diff in Diff (DID) model, it is found that event have significantly reduce the idiosyncratic risk of the stocks that have been included into the index, which proved that the overall advantages of the capital market opening up policy outweigh the disadvantages.
\end{abstract}

Keywords: Capital market opening up, Idiosyncratic risk, Liquidity.

${ }^{1}$ PBC School of Finance, Tsinghua University, China.

Article Info: Received: February 1, 2022. Revised: February 17, 2022.

Published online: February 22, 2022. 


\section{Introduction}

\subsection{Background}

Historically, the opening of the capital market to the outside world has always been an important part of the opening up of the financial industry in China. Since 2004, China's policy makers have introduced a series of measures to help China's capital market open to the outside world, such as the improvement of listed company governance, the reform of the issuance system, and the active introduction of QFII/RQFII scheme, and the Shanghai-Hong Kong Stock Connect, Shenzhen-Hong Kong Stock Connect, Bond Connect etc. After rapid development in the past two decades, China's capital market has become the second largest capital market in the world after the United States. The overall scale of stocks and bonds market is the second in the world, and the scale of government bonds is the third (Figure 1). Capital market has played a very important role in promoting the rise of China's economy.
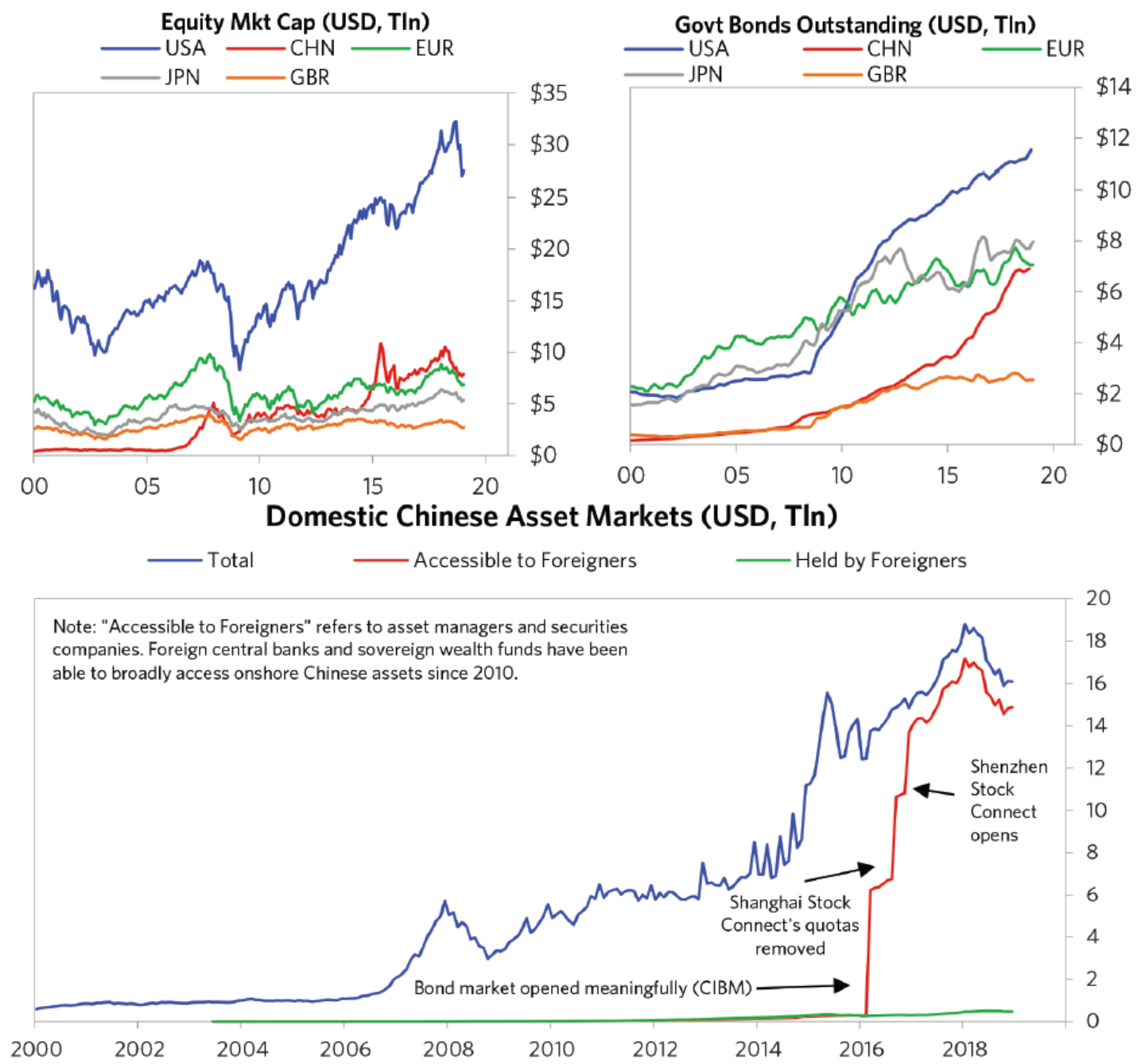

Figure 1: China's Capital Market size 
However, Chinese assets proportion in foreign investors' portfolios were even less than $1 \%$ as of 2019, which does not match China's capital market size and economic scale ranking in the world. The main reason is that there are too few channels and thus too few assets investable for foreign investors. This situation did not change substantially until the opening of the Bond market and the opening of the Shanghai and Shenzhen-Hong Kong Stock Connect in 2016. After 2016, the investable assets by foreign investors have reached more than $90 \%$ of the entire domestic capital market (Figure 1). The "A-share inclusion in the MSCI index" event starting from 2018 is a classic exogenous event that has further improved the degree of openness of China's capital market. The inclusion event was expected to bring hundreds of billions of dollars of external capital to China in next 5 years, and the proportion of foreign investors is expected to increase significantly.

\subsection{The representative events of capital market opening: "A-share inclusion in the MSCI index"}

The full name of MSCI is Morgan Stanley Capital International, a well-known index company in the United States. A series of MSCI indexes it has launched are widely used by institutional investors as investment benchmarks. The most important of the indices it compiles and is tracked by the most institutional investors are three indices compiled by region: MSCI All Country World (ACWI), MSCI ACWI exUS and MSCI Emerging Markets. In the past two decades, the scale of China's economy and capital market has grown rapidly, and there was a strong demand for foreign investors to get exposure to China and share China's economy growth, however, three previous attempts to add China's stock into MSCI index had failed. During this period, in order to promote the internationalization of China's capital market, the regulators in China have carried out supporting reforms on several basic policies, such as the QFII and RQFII systems, shortening the suspension and resumption period to reduce trading suspension resistance, relaxing foreign investment access conditions, and shortening approvals time limit, expand investment scope etc. With the gradual resolution of the concerns of many foreign investors, MSCI finally announced in 2017 that it had successfully included A shares in its emerging market index in a new round of market consultation. The specific implementation plan was that the first inclusion ratio (inclusion factor) is 5\%, and the implementation will be carried out in two batches: the first 2.5\% will be announced on May 14, 2018 and the specific stock list and weights are officially implemented on the close of May 31, 2018; The second 2.5\% will be announced on August 13, 2018 and implemented on close of September 3. If the effect is good after the implementation, it is expected that MSCI will continue to gradually increase the inclusion ratio (in fact MSCI increased the inclusion factor to $10 \%, 15 \%$ and 20\% on May 28, August 27 and November 26, 2019, respectively). 
The most direct impact of "A-share inclusion in the MSCI index" is that it will introduce a massive and long-term capital inflow to the A-share market. MSCI indexes are the investment benchmarks most used by global institutional institutions, and there is a huge amount of capital tracking these indexes: as of 2017, the global asset management scale based on the MSCI index was US\$12.4 trillion, of which ETF products were US\$700 billion. The scale of funds tracking the MSCI Global Index is US\$3.7 trillion, of which passive funds are about US\$350 billion. The funds tracking the MSCI Emerging Markets Index are at scale of US\$1.9 trillion, of which passive funds are about US\$200 billion. Although the initial capital inflow to A-shares is limited, it is expected to bring a total capital inflow of US\$210 billion in the next five years, which will be conducive to the long-term healthy development of the A-share market.

\section{Literature review}

This paper focused on the opening up of the domestic capital market (that is, the introduction of foreign investment into the domestic market). The relevant research in this area include in below three categories: one is to study its relationship with a country's economic growth with the opening up; second is to study impact of opening up on domestic stocks. Such as the impact on overall volatility and idiosyncratic volatility; the third is to study the impact of opening up on domestic bond market, in addition to the impact on volatility, there are studies on the impact on liquidity and FX rates as well. In addition, this paper also sorts out the relevant literature on whether the idiosyncratic risk is embodied as "noise" or " idiosyncratic information".

It is generally believed that the opening of the capital market to the outside world is conducive to promoting capital inflow and has a positive effect on economic growth, but it is also a double-edged sword and may endanger financial market stability. Regarding the impact of the opening of the capital market on the stock market, there are mainly two types of views: On one hand, Brennan and Cao (1997) showed the opening of the capital market will increase the volatility of the stock market. They found that when American investors invest in other countries, no matter in developed or emerging markets, it is easier to buy high and sell low, which will aggravate the volatility of the local stock market and amplify the transmission of international risks. On the other hand, it is believed that the opening of the capital market is conducive to the stability of the stock market. Li et. al (2011) found that the entry of foreign capital can improve the quality of information disclosure of listed companies, thereby reducing market volatility and transaction costs. Regarding the impact of bond market opening, Burger and Warnock (2009) argue that the opening of emerging market bond markets has improved the stability of global financial markets. 


\subsection{The impact of capital market opening on a country's economic growth}

There are more consensus in academic research in this topic, many literatures believe that there is a positive relationship between the capital market opening and economic growth. Bekaert et. al (2005) confirmed that the opening of the stock market has a significant positive correlation with GDP growth, and estimated that the economy increased by $1 \%$ more every five years on average. Gupta et. al (2009) studied the relationship between the opening of the stock market and the growth of some industries in emerging market countries, and found that industries with better growth opportunities and stronger external dependencies grew faster after the opening of the stock market. Using data from 45 developed and emerging market countries, Bussiere et. al (2008) found that financial liberalization can lead to accelerated economic growth in the short term, but a return to the long-term average in the medium term. They also found that the effect of finance liberalization in developed countries is better and longer than that in emerging market countries, and quantified that the economy can grow by $1.5 \%$ more in the first five years of financial liberalization.

There are also dissenting voices. Angkinand et. al (2010) constructed a theoretical model to analyze why financial liberalization is more likely to bring financial crises. It showed after financial liberalization, there will be rapid economic growth with low risk in the short term, but the risk of a banking crisis will increase in the long run, especially when the intensity of capital controls is relatively weak. Kaminsky and Reinhart et. al (1999) argued that financial liberalization led to financial crises. Stiglitz (2010) believes that financial integration does not necessarily bring better stability to the financial system. The best example is that during financial crisis, risk in one region will quickly transforms into a global crisis, so it is possible that complete financial closure is better than financial integration.

\subsection{The impact of Stock market opening up}

Many literatures show that the opening of the capital market improves the level of corporate governance and pricing efficiency, and reduces the risk of the stock market. Ferreira et. al (2008) used data from 27 countries to find that companies with a high proportion of foreign capital and independent institutions have higher valuations, better operating performance, and lower capital expenditures, indicating that the opening of the capital market will help strengthen corporate governance. $\mathrm{Li}$ et. al (2014) analyzed the data of companies listed on both A-shares and H-shares in China, and found that $\mathrm{H}$-shares that can be directly invested by foreign capital contain significantly more firm information than A-shares, pointing out that the opening of the capital market can improve the level of corporate governance. Fang et. al (2015) found that the higher the proportion of US institutional investors in the stock market of emerging market countries, the higher the comparability of accounting information and the higher the pricing efficiency. Li et. al (2011), Bae et. al (2012) have empirically proved that capital market opening can reduce stock market volatility, maintain capital market stability and improve stock pricing 
efficiency. Kim and Singal (2000), Bekaert et. al (2005) all found that capital market opening reduces stock price volatility, and Schuppli et. al (2010) found that foreign investors have a stabilizing effect on China's stock market. Gupta et. al (2009) found that after foreign capital entered the local stock market, it shared the risk of domestic capital by providing additional financing channels, thereby reducing market risk. Umutlu et. al (2010) found that financial liberalization reduces idiosyncratic volatility and thus aggregate volatility.

There are also studies that believe that the opening of the capital market has exacerbated market volatility. For example, Stiglitz (2000) believes that after opening up, the linkage with the international market is intensified, and the risk contagion effect intensifies the risk of capital market volatility. Choe et. al (2005) used high-frequency data from the Korean market and found that foreign investors have higher transaction costs and higher short-term behavior than domestic investors, resulting in greater market volatility. Chan et. al (2008) found that information asymmetry can explain a large part of the discount of B shares through the study of China's A/B shares. In the case of information asymmetry, the cost of foreign information collection and analysis is relatively high, so investment decisions have high noise, resulting in increased stock price volatility.

\subsection{The impact of Bond market opening up}

First, many literatures have discussed whether emerging markets can sustainably develop domestic bond markets. On the one hand, Eichengreen et al. (2002) believe that developing countries have "original sins" such as imperfect legal systems and high inflation, which cannot be overcome by themselves and can only be solved by introducing international organizations. On the other hand, La Portal et al. (1997) argue that emerging market countries can continue to improve legal systems and investor protection mechanisms, refuting the existence of the so-called "original sin". In this regard, Burger and Warnock (2006) conducted an in-depth comparative analysis using the bonds of 49 countries and found that one is that the legal system and policy stability are crucial to the development of the bond market; the other is the so-called original sin of emerging market countries does not exist, thus supporting the study by La Portal et al. (1997).

Secondly, many literatures have studied bond market opening up from the perspectives of the impact to global financial system, the impact on interest rates and interest rate volatility, the impact on bond liquidity, the impact on exchange rates, and the impact on financial risk transmission, most of which are for emerging market countries.

From the perspective of the impact on the global financial system, Burger and Warnock (2009) believe that the opening of the emerging market bond market improves the stability of the global financial market, mainly because it reduces the dependence of emerging market countries on foreign currency debt, which often is one of the main reasons for the financial crisis. From the perspective of the impact on interest rates, IMF (2005), MSCI Barra and IMF (2010), Roldos (2004) and 
many other articles all show that after the bond market opens up, the demand brought by foreign capital has increased significantly, which has lowered the bond market. yields on bonds. From the impact on bond liquidity, the conclusion is relatively consistent, that is, the participation of foreign investors can significantly increase the liquidity of domestic bonds. From the perspective of the impact on exchange rates, Miyajima et al. (2015) showed that exchange rate risk is one of the most important factors for emerging market countries. Gyntelberg and Remolona (2007), Miyajima et al. (2014) both believe that a large part of the high yield of emerging market country bonds comes from compensation for exchange rate fluctuation risks. Turner 2012 believe that the internationalization of local currency bonds in emerging market countries depends on whether the foreign investors are willing to take on exchange rate risks, and on the ability and tools to hedge exchange rate risks.

\section{Study on stock market opening}

The exogenous event "A-share inclusion in the MSCI index" in 2018 created a good opportunity for us to study the financial market opening up impact on volatility, especially on idiosyncratic volatility, from both the theoretical and empirical point of view. From theoretical point of view, we proposed two opposing hypotheses to explain the impact of "A-share inclusion in the MSCI index" on the idiosyncratic volatility of stock prices: The "Information quality improved hypothesis" and the "Trading noise increased hypothesis". From empirical point of view, this paper uses the volatility of residual returns after the regression of the CAPM model to calculate the stock price idiosyncratic volatility, and then establishes a Diff in Diff (DID) empirical model.

\subsection{Theoretical model}

\subsubsection{Information quality improved hypothesis}

With the official implementation of "A-share inclusion in the MSCI index", the global market influence of A shares will be greatly enhanced. On the one hand, passive funds tracking the MSCI index around the world will "passively" buy positions in A shares, on the other hand, A shares will also be included in global asset manager's allocation research framework, which requires more in-depth research and judgment on China's capital market. This requires A-share target companies to have higher information disclosure quality and corporate governance efficiency, thereby can attracting more buying flows. In addition, the transaction execution of "A-share inclusion in the MSCI index" will be implemented through the Shanghai-Hong Kong Stock Connect, Shenzhen-Hong Kong Stock Connect, which have been in operation for several years and have been operating well, reducing the transaction threshold and transaction costs for foreign investors. Trading via stock connects schemes addressed the concerns of foreign investors that the flow of funds in and out of China may be regulated

One main difference the "A-share inclusion in the MSCI index" will bring is the 
different market participants, for now trading activities in domestic market is dominated by local retail investors, while the foreign investors who track the MSCI indices are mainly institutional investors. Institutions investment style is based on fundamental analysis and index tracking rules, and they have stronger research capabilities, information collection and processing capabilities and trading capabilities, which can respond faster to changes in market conditions and improve the quality of information implied by stock prices. For example, the research of Bae et al. (2012) shows that foreign investors have a greater advantage in collecting and processing international market information. As the information quality of their stock prices entering the local market improves, the stock price response time lag decreases. Secondly, foreign investors can help strengthen corporate governance by playing a supervisory role. For example, Li et al. (2011) found that the supervisory role of foreign institutional investors helps to promote market stability; Ferreira et al. (2008) verified that the addition of foreign investors makes it more difficult for domestic companies to manipulate information. Third, the opening of the stock market to foreign investors can prompt listed companies to improve the quality of information disclosure. For example, Fang et al. (2015) found that the higher the proportion of US institutional investors in the stock markets of emerging market countries, the higher the comparability of their accounting information with US standards, and the better the quality of information disclosure.

Through the above analysis, by introducing more foreign institutional investors, "Ashare inclusion in the MSCI index" event will help to leverage the information advantages, investment philosophy advantages and supervision advantages of institutional investors, and thus reduce the idiosyncratic volatility of stock prices. In this regard, the hypothesis $1 \mathrm{a}$ is proposed.

Hypothesis 1a. The implementation of "A-share inclusion in the MSCI index" can effectively reduce the idiosyncratic risk of the underlying stock that's been added into the index.

\subsubsection{Trading noise increased hypothesis}

The implementation of "A-share inclusion in the MSCI index" will strengthen the linkage between the A-share market and the international market, and the contagion effect of external risk events will be stronger. At the same time, the short-term in and out of foreign hot money may bring more noise trading activities, thereby exacerbating stock price volatility.

For one, there are many academic papers on the stronger linkage with the international market by the opening of the capital market and the aggravation of the risk contagion effect. Demir (2004) used Turkish data to verify the amplification of stock price volatility risk, and Stiglitz (2000) proved that this effect may be amplified in a relatively weak regulatory environment. Second, the "hot money" effect of foreign investors will prompt them to pursue short-term investments with higher profits and not pay attention to long-term performance (Brennan and Cao, 1997), thus bringing higher short-term performance pressure to listed companies. 
Moreover, investors' short-term market behavior may increase stock price volatility (Choe et al., 2005).

Based on the above analysis, "A-share inclusion in the MSCI index" may lead to more noise trading, which will lead to an increase in idiosyncratic volatility. In this regard, the hypothesis $1 \mathrm{~b}$ is proposed.

Hypothesis 1b. The implementation of "A-share inclusion in the MSCI index" will increase the idiosyncratic risk of the underlying stock that's been added into the index.

\subsection{Empirical model}

MSCI announced the inclusion of A shares in its emerging market index in June 2017, and gave market participants one year to prepare, and then officially implemented at the end of May 2018. In addition, in order to further reduce the market impact, the initial inclusion ratio is only $5 \%$, and the implementation is carried out twice: the first $2.5 \%$ batch included 234 stocks, announced on May 14, 2018, implemented on May 31, 2018. The second 2.5\% batch was announced on August 13, 2018, included 236 stocks, implemented on close of September 3. Based on the above background, this paper designs the following Diff in Diff (DID) model to test the relationship between the opening of the capital market and the idiosyncratic volatility of underlying stocks that's been added into index.

Idiosyncratic Risk $_{\mathrm{i}, \mathrm{t}+1}=\alpha_{0}+\alpha_{1}$ MSCI $_{i}+\alpha_{2}$ After $_{t}+\alpha_{3}$ MSCI $_{i} \times$ After $_{t}$

$+\sum$ Controls $_{i, t}+$ Year $_{t}+\mu_{i, t}$

Idiosyncratic Risk is dependent variable, $\mathrm{i}$ represents different stocks and $\mathrm{t}$ represents different time. "MSCI" is the dummy variable of the "A-share inclusion in the MSCI index" event, MSCI=1 means a stock in included in the MSCI Index, otherwise $\mathrm{MSCI}=0$. "After" is a dummy variable that equals to 1 if $\mathrm{t}$ is after a certain date (will elaborate more later). $\alpha_{3}$ is the key variable we want to observe and its an interaction term equal to the product of dummy variable MSCI and After. If regression result shows $\alpha_{3}$ is significantly negative, then means idiosyncratic volatility reduced and proved hypothesis 1a; if results shows $\alpha_{3}$ is significantly positive, then means idiosyncratic volatility increased and proved hypothesis $1 \mathrm{~b}$. 


\section{Main Results}

\subsection{Variable definition}

\subsubsection{Idiosyncratic Risk}

This paper uses weekly stock price return to calculate monthly stock price idiosyncratic volatility (showed as annualized). Specific calculation method as below: firstly, use the weekly stock return minus the risk-free interest rate in the same period, and then use the weekly return of the CSI300 Index as the beta (without considering cash dividend reinvestment) to obtain the residual of the regression results of CAPM model; Secondly, calculate variance of the residual return of each individual stocks per month, and then annualized, we got the proxy variable of idiosyncratic volatility of stock price (var_capm_w_ann). In addition, we also calculate the raw volatility of stocks in the same period as a comparison (var_raw_w_ann).

\subsubsection{MSCI and After dummy variables}

"MSCI" is the dummy variable of the "A-share inclusion in the MSCI index" event, MSCI $=1$ means a stock in included in the MSCI Index, otherwise MSCI=0. "After" is a dummy variable that equals to 1 if $t$ is After a certain date, we defines After $1=1$ for dates after January 2017 (when no information about a shares included in MSCI index has been announced), After $2=1$ for dates after June 2017 (the time point of first announcement), After $3=1$ for dates after January 2018 (middle point between time point of announcement and first execution), After $4=1$ for dates after June 2018 (the first actual implementation time point, with emphasis on the investigation time point), and After5=1 for dates after September 2018 (the second implementation time point), otherwise After $=0$.

\subsubsection{Control variables}

We selected the variables such as $\mathrm{P} / \mathrm{E}$ ratio, $\mathrm{P} / \mathrm{B}$ ratio, book to market cap ratio, financial liability ratio, company size, dummy variable for whether the auditors are from the four major accounting firms (PWC, Deloitte, Ernst \& Young, KPMG), dummy variable for whether the auditors are from overseas accounting firms, the number of analysts covering stocks, the shareholding ratio of foreign investors. See Table 1 for detailed specific definitions. 
Table 1: Control Variables Definition

\begin{tabular}{|l|l|}
\hline \multicolumn{1}{|c|}{ Variable } & \multicolumn{1}{c|}{ Definition } \\
\hline var_raw & Stock raw volatility (Annualized) \\
\hline var_capm_w_ann & $\begin{array}{l}\text { Stock idiosyncratic volatility based on CAPM model } \\
\text { (Annualized) }\end{array}$ \\
\hline MSCI1/2 & $\begin{array}{l}\text { Dummy variable, MSCI=1 if stock i is included in MSCI } \\
\text { index,otherwise }=0 . \\
\text { - MSCI1=1 if stock is added in first batch on May 2018. } \\
\text { - MSCI2=1 if stock is added in second batch on Sep 2018. }\end{array}$ \\
\hline After1/2/3/4/5 & $\begin{array}{l}\text { Dummy variable, After=1 after certain time, otherwise = } \\
\text { - After1=1 for dates after Jan 2017 } \\
\text { - After2=1 for dates after June 2017 } \\
\text { - After3=1 for dates after Jan 2018 } \\
\text { - After4=1 for dates after June 2018 } \\
\text { - After5=1 for dates after Sep 2018 }\end{array}$ \\
\hline PE_ratio & Price to Earning ratio \\
\hline PB_ratio & Price to Book ratio \\
\hline BM_ratio & Book to Market cap ratio \\
\hline Fin_Lev & Financial liability ratio \\
\hline AnaAttention & Number of analysts covering the stock \\
\hline CompanySize_log & Company Market cap (log) \\
\hline Big4 & $\begin{array}{l}\text { Dummy variable, if auditors are from the four major } \\
\text { accounting firms (PWC, Deloitte, Ernst \& Young, } \\
\text { KPMG)=1, otherwise = 0. }\end{array}$ \\
\hline Outside_Audit & $\begin{array}{l}\text { Dummy variable, if the auditors are from overseas } \\
\text { accounting firms=1, otherwise=0. }\end{array}$ \\
\hline TotInsHoldper & Overall Institutional investor holding\% \\
\hline FdHoldper & Pension fund holding\% \\
\hline SecCorpHoldPer & Security Firm holding\% \\
\hline QFIIHoldPer & QFII holding \% \\
\hline InsuComHoldPer & Insurance company holding\% \\
\hline SocSecFdHoldPer & China's National Social Securities Fund Holding\% \\
\hline OthInsHoldPer & Other institutional investor holding\% \\
\hline
\end{tabular}


The data of this paper comes from CSMAR and RESSET database. The sample period for A-share listed companies is from early 2012 to end of 2019. The data screening conditions are as follows: the samples of companies with annual stock weekly return data less than 26 weeks are excluded; eliminated samples with missing data; $1 \%$ winsorize for continuous variables.

\subsection{Descriptive statistics}

Table 2 lists the statistical results of sample variables in this study. Due to large number of combinations of MSCI and After, we choose below set as an example. We take MSCI $1=1$ and After $4=1$, that is the first actual implementation time point of "A-share inclusion in the MSCI index" event, and M1A4 is the interaction term of the two. Table 2 is the descriptive statistics of the overall samples, we can have below observations: first, the average of systemic risk (i.e. raw volatility, var_raw_w_ann) is higher than that of non-systemic risk (i.e. idiosyncratic volatility, var_capm_w_ann); Second, the average PE ratio of A share is as high as 86 times; Third, there are on average 8 analysts tracking each stock; Fourth, only $7.2 \%$ of the companies using the big four oversea audit firms.

Table 3 compares the samples of stocks that's been included into the MSCI Index vs. not included ones. The following observations can be made: first, both the systemic risk and non-systemic risk of the included stocks are lower than those not included; Second, almost all indicators of the underlying stocks included in the MSCI index were "better" than those not included stocks, included stocks have lower $\mathrm{P} / \mathrm{E}$ ratio and $\mathrm{P} / \mathrm{B}$ ratio, covered by more analysts (more than twice on average), higher proportion of using big four oversea audit firms, higher proportion of institutional investors holding \%, etc.

In Table 4 we tested for multicollinearity, and the results show that there is no obvious multicollinearity problem between variables. 
Table 2: Total sample descriptive statistics

\begin{tabular}{|l|c|c|c|c|c|c|}
\hline VarName & Obs & Mean & SD & Min & Median & Max \\
\hline var_raw_w_ann & 2607 & 0.204 & 0.055 & 0.039 & 0.203 & 0.422 \\
\hline var_capm_w_ann & 2607 & 0.148 & 0.050 & 0.034 & 0.142 & 0.408 \\
\hline MSCI1 & 2607 & 0.087 & 0.283 & 0.000 & 0.000 & 1.000 \\
\hline After4 & 2607 & 0.255 & 0.129 & 0.000 & 0.209 & 0.817 \\
\hline M1A4 & 2607 & 0.019 & 0.066 & 0.000 & 0.000 & 0.561 \\
\hline PE_ratio & 2607 & 86.963 & 94.034 & 5.439 & 51.970 & 1037.684 \\
\hline PB_ratio & 2607 & 3.531 & 2.406 & 0.667 & 2.964 & 26.206 \\
\hline BM_ratio & 2607 & 0.633 & 0.196 & 0.111 & 0.632 & 1.080 \\
\hline AnaAttention & 2607 & 8.286 & 7.615 & 1.000 & 5.675 & 52.832 \\
\hline CompanySize_log & 2607 & 22.154 & 1.460 & 16.362 & 21.901 & 30.654 \\
\hline Big4 & 2607 & 0.072 & 0.244 & 0.000 & 0.000 & 1.000 \\
\hline Outside_Audit & 2607 & 0.032 & 0.161 & 0.000 & 0.000 & 1.000 \\
\hline Fin_Lev & 2607 & 1.662 & 12.131 & -339.16 & 0.844 & 392.865 \\
\hline TotInsHoldperA & 2607 & 0.307 & 0.182 & 0.000 & 0.282 & 0.983 \\
\hline FdHoldperA & 2607 & 0.023 & 0.029 & 0.000 & 0.013 & 0.208 \\
\hline SecCorpHoldPerA & 2607 & 0.003 & 0.004 & 0.000 & 0.001 & 0.056 \\
\hline QFIIHoldPerA & 2607 & 0.001 & 0.006 & 0.000 & 0.000 & 0.180 \\
\hline InsuComHoldPerA & 2607 & 0.003 & 0.023 & 0.000 & 0.000 & 0.928 \\
\hline SocSecFdHoldPerA & 2607 & 0.003 & 0.005 & 0.000 & 0.001 & 0.049 \\
\hline OthInsHoldPerA & 2607 & 0.271 & 0.179 & 0.000 & 0.240 & 0.981 \\
\hline
\end{tabular}

Table 3: Included vs. Not Included stocks

\begin{tabular}{|l|c|c|c|c|c|c|}
\hline & \multicolumn{2}{|c|}{ Included into MSCI Index } & \multicolumn{2}{c|}{ Not Included into MSCI Index } \\
\hline VarName & Obs & Mean & Median & Obs & Mean & Median \\
\hline var_raw_w_ann & 228 & 0.160 & 0.154 & 2379 & 0.209 & 0.207 \\
\hline var_capm_w_ann & 228 & 0.111 & 0.106 & 2379 & 0.152 & 0.146 \\
\hline MSCI1 & 228 & 1.000 & 1.000 & 2379 & 0.000 & 0.000 \\
\hline After4 & 228 & 0.220 & 0.203 & 2379 & 0.259 & 0.209 \\
\hline M1A4 & 228 & 0.220 & 0.203 & 2379 & 0.000 & 0.000 \\
\hline PE_ratio & 228 & 39.195 & 26.621 & 2379 & 91.547 & 55.582 \\
\hline PB_ratio & 228 & 2.777 & 2.105 & 2379 & 3.604 & 3.031 \\
\hline BM_ratio & 228 & 0.729 & 0.794 & 2379 & 0.624 & 0.626 \\
\hline AnaAttention & 228 & 18.898 & 17.696 & 2379 & 7.219 & 5.111 \\
\hline CompanySize_log & 228 & 24.634 & 24.466 & 2379 & 21.913 & 21.794 \\
\hline Big4 & 228 & 0.355 & 0.000 & 2379 & 0.045 & 0.000 \\
\hline Outside_Audit & 228 & 0.199 & 0.000 & 2379 & 0.016 & 0.000 \\
\hline Fin_Lev & 228 & 2.779 & 1.499 & 2379 & 1.555 & 0.802 \\
\hline TotInsHoldperA & 228 & 0.411 & 0.378 & 2379 & 0.297 & 0.270 \\
\hline FdHoldperA & 228 & 0.042 & 0.032 & 2379 & 0.022 & 0.012 \\
\hline SecCorpHoldPerA & 228 & 0.002 & 0.001 & 2379 & 0.003 & 0.001 \\
\hline QFIIHoldPerA & 228 & 0.005 & 0.000 & 2379 & 0.001 & 0.000 \\
\hline InsuComHoldPerA & 228 & 0.011 & 0.002 & 2379 & 0.002 & 0.000 \\
\hline SocSecFdHoldPerA & 228 & 0.005 & 0.002 & 2379 & 0.003 & 0.000 \\
\hline OthInsHoldPerA & 228 & 0.341 & 0.307 & 2379 & 0.264 & 0.231 \\
\hline
\end{tabular}


Table 4: Multicollinearity test

\begin{tabular}{|l|l|l|}
\hline \multicolumn{1}{|c|}{ Variable } & VIF & 1/VIF \\
\hline CompanySize_log & 3.87 & 0.2583 \\
\hline BM_ratio & 3.18 & 0.3143 \\
\hline PB_ratio & 2.51 & 0.3979 \\
\hline Year_num & 2.48 & 0.4037 \\
\hline After4 & 2.08 & 0.4797 \\
\hline Fin_Lev & 1.88 & 0.5307 \\
\hline MSCI1 & 1.83 & 0.5465 \\
\hline AnaAttention & 1.61 & 0.6229 \\
\hline OthInsHoldPerA & 1.49 & 0.6716 \\
\hline Big4 & 1.43 & 0.7007 \\
\hline M1A4 & 1.42 & 0.7049 \\
\hline FdHoldperA & 1.37 & 0.7283 \\
\hline Outside_Audit & 1.31 & 0.7608 \\
\hline QFIIHoldPerA & 1.14 & 0.8747 \\
\hline PE_ratio & 1.13 & 0.8822 \\
\hline SocSecFdHoldPerA & 1.13 & 0.8823 \\
\hline InsuComHoldPerA & 1.08 & 0.9228 \\
\hline SecCorpHoldPerA & 1.02 & 0.9787 \\
\hline Mean VIF & 1.78 & \\
\hline
\end{tabular}

\subsection{Main results}

Table 5 lists the main empirical results. The difference between the three column models is that different time points are used to calculate the interaction term MSCI x After. After $2=1$ in column (1) is set after June 2017, which is the "announcement" time for A shares to be included in the MSCI index, and the interaction term is M1A2; After4 = 1 in column (2) is set after June 2018, which is the "actual implementation" time for A shares to be included in MSCI index, and the interaction term is M1A4; After1 = 1 in column (3) is set after January 2017. At this time point, there is no information that A shares will be included in the MSCI index, and the interaction term is M1A1. The purpose of this design is to show that as time goes by, the underlying stocks' volatility will change from no information at all (column 3 ), to only announcement without implementation (column 1), and then to actual implementation (column 2). It should be seen that the coefficient of the interaction term will change from non-significant to significant, and from positive or negative to significant negative. Above points can be verified from the following regression results. 
The results show that the coefficient of M1A4 in the second column is significantly negatively correlated with the idiosyncratic volatility of stock price (significant at $1 \%$ level). In contrast, although the coefficient of M1A2 in the first column model is also negative, the absolute value of and the significance of the coefficient both decreased (significant at 10\%), what's more we can see that the coefficient of M1A1 in the third column model decreased again and it's not significant at all.

Table 5: Regression results

\begin{tabular}{|c|c|c|c|}
\hline & (1) & (2) & (3) \\
\hline & $\begin{array}{c}\text { After } 201706 \\
\text { First Announcement }\end{array}$ & $\begin{array}{c}\text { After } 201806 \\
\text { First Implementation }\end{array}$ & $\begin{array}{c}\text { After 201701 } \\
\text { No Inclusion info }\end{array}$ \\
\hline \multirow[t]{2}{*}{ M1A2 } & $-0.002 *$ & & \\
\hline & $(-1.651)$ & & \\
\hline \multirow[t]{2}{*}{ M1A4 } & & $-0.010 * * *$ & \\
\hline & & $(-7.718)$ & \\
\hline \multirow[t]{2}{*}{ M1A1 } & & & 0.000 \\
\hline & & & $(0.380)$ \\
\hline \multirow[t]{2}{*}{ After2 } & $0.010 * * *$ & & \\
\hline & $(12.552)$ & & \\
\hline \multirow[t]{2}{*}{ After4 } & & 0.052 & \\
\hline & & $(67.865)$ & \\
\hline \multirow[t]{2}{*}{ After1 } & & & -0.067 \\
\hline & & & $(-75.859)$ \\
\hline \multirow[t]{2}{*}{ PE_ratio } & $0.000 * * *$ & $0.000 * * *$ & $0.000 * * *$ \\
\hline & $(27.251)$ & $(33.067)$ & $(21.225)$ \\
\hline \multirow[t]{2}{*}{ PB_ratio } & 0.015 & 0.016 & 0.013 \\
\hline & $(80.515)$ & $(87.755)$ & $(69.577)$ \\
\hline \multirow[t]{2}{*}{ BM_ratio } & -0.112 & -0.145 & -0.096 \\
\hline & $(-55.315)$ & $(-70.217)$ & $(-48.102)$ \\
\hline \multirow[t]{2}{*}{ AnaAttention } & $-0.001 * * *$ & -0.002 & $-0.001 * * *$ \\
\hline & $(-36.297)$ & $(-47.598)$ & $(-25.350)$ \\
\hline \multirow[t]{2}{*}{ CompanySize_log } & $0.013 * * *$ & $0.017 * * *$ & $0.010 * * *$ \\
\hline & $(20.195)$ & $(26.883)$ & $(15.471)$ \\
\hline \multirow[t]{2}{*}{ Big4 } & $-0.006 * * *$ & $-0.007 * * *$ & $-0.005 * * *$ \\
\hline & $(-2.972)$ & $(-3.518)$ & $(-2.638)$ \\
\hline \multirow[t]{2}{*}{ Outside_Audit } & -0.000 & 0.000 & 0.002 \\
\hline & $(-0.025)$ & $(0.123)$ & $(0.894)$ \\
\hline \multirow[t]{2}{*}{ Fin_Lev } & $0.002 * * *$ & $0.001 * * *$ & $0.002 * * *$ \\
\hline & $(5.034)$ & $(3.805)$ & $(7.232)$ \\
\hline \multirow[t]{2}{*}{ FdHoldperA } & $-0.104 * * *$ & $-0.137 * * *$ & $0.023 * * *$ \\
\hline & $(-4.202)$ & $(-5.566)$ & $(4.321)$ \\
\hline \multirow[t]{2}{*}{ SecCorpHoldPerA } & $-0.072 * *$ & $-0.076^{* *}$ & -0.032 \\
\hline & $(-2.058)$ & $(-2.162)$ & $(-1.272)$ \\
\hline \multirow[t]{2}{*}{ QFIIHoldPerA } & $0.156 * * *$ & $0.158 * * *$ & $0.151 * * *$ \\
\hline & $(3.232)$ & $(3.278)$ & $(3.625)$ \\
\hline
\end{tabular}




\begin{tabular}{|l|c|c|c|}
\hline InsuComHoldPerA & $0.074 * * *$ & $0.090 * * *$ & $0.024 *$ \\
\hline & $(2.600)$ & $(3.183)$ & $(1.649)$ \\
\hline SocSecFdHoldPerA & $0.113 * * *$ & $0.199 * * *$ & $0.101 * * *$ \\
\hline & $(3.302)$ & $(5.829)$ & $(4.197)$ \\
\hline OthInsHoldPerA & $-0.144 * * *$ & $-0.139 * * *$ & -0.001 \\
\hline & $(-5.926)$ & $(-5.764)$ & $(-0.791)$ \\
\hline cons & $5.093 * * *$ & 18.579 & -16.741 \\
\hline & $(12.877)$ & $(46.122)$ & $(-40.833)$ \\
\hline
\end{tabular}

Note:*/**/*** represents significance at $10 \% / 5 \% / 1 \%$ level, number in brackets are t-statistics.

From above empirical results we can find that after the actual implementation of "A-share inclusion in MSCI index", compared with stocks that's not been included, the included stocks' idiosyncratic volatility have decreased by about $9 \%$ (the calculation method is to use the coefficient of M1A4 in the model in column 2 of Table 5 to divide by the average stock idiosyncratic volatility of the included stocks in Table 3, 0.111, - 0.01/ $0.111=-9 \%$ ), It shows that even when the initial inclusion ratio is only $5 \%$ and implemented by two batches, the idiosyncratic volatility of included stock has decreased significantly, which supports the hypothesis 1a. It shows that the capital market opening-up policy of "A-share inclusion in the MSCI index" is helpful to reduce the idiosyncratic volatility in China's stock market.

\section{Conclusion}

In the past two decades, China's capital market has developed rapidly, and the overall scale has reached 31 trillion US dollars, making it the second largest capital market in the world after the United States. The opening of the bond market in 2016 and the opening of the Shanghai-Shenzhen-Hong Kong Stock Connect have accelerated this phenomenon, since 2018, China's domestic stocks and government bonds have been successively included in multiple international indices, making China's domestic capital market attract more and more foreign capital. This paper studies the impact of a higher proportion of foreign investors on the volatility, and especially the idiosyncratic volatility. By constructing a Diff in Diff (DID) model, it is found that event have significantly reduce the idiosyncratic risk of the stocks that's been included into the index, which proved that the overall advantages of the capital market opening up policy outweigh the disadvantages. 


\section{References}

[1] Angkinand, A.P., Sawangngoenyuang, W. and Wihlborg, C. (2010). Financial liberalization and banking crises: A cross-country analysis. International Review of Finance, 10(2), pp.263-292.

[2] Bae, K.H., Ozoguz, A., Tan, H. and Wirjanto, T.S. (2012). Do foreigners facilitate information transmission in emerging markets? Journal of Financial Economics, 105(1), pp.209-227.

[3] Bekaert, G., Harvey, C.R. and Lundblad, C. (2005). Does financial liberalization spur growth?. Journal of Financial economics, 77(1), pp.3-55.

[4] Brennan, M.J. and Cao, H.H. (1997). International portfolio investment flows. The Journal of Finance, 52(5), pp.1851-1880.

[5] Bussiere, M. and Fratzscher, M. (2008). Financial openness and growth: Shortrun gain, long-run pain?. Review of International Economics, 16(1), pp.69-95.

[6] Chan, K., Menkveld, A.J. and Yang, Z. (2008). Information asymmetry and asset prices: Evidence from the China foreign share discount. The Journal of Finance, 63(1), pp.159-196.

[7] Choe, H., Kho, B.C. and Stulz, R.M. (2005). Do domestic investors have an edge? The trading experience of foreign investors in Korea. The Review of Financial Studies, 18(3), pp.795-829.

[8] Demir, F. (2004). A failure story: Politics and financial liberalization in Turkey, revisiting the revolving door hypothesis. World Development, 32(5), pp.851869.

[9] Fang, V.W., Maffett, M. and Zhang, B. (2015). Foreign institutional ownership and the global convergence of financial reporting practices. Journal of Accounting Research, 53(3), pp.593-631.

[10] Ferreira, M.A. and Matos, P. (2008). The colors of investors' money: The role of institutional investors around the world. Journal of Financial Economics, 88(3), pp.499-533.

[11] Gupta, N. and Yuan, K. (2009). On the growth effect of stock market liberalizations. The Review of Financial Studies, 22(11), pp.4715-4752.

[12] Kim, E. and Singal, V. (2000). Stock market openings: Experience of emerging economies. The Journal of Business, 73(1), pp.25-66.

[13] Li, D., Nguyen, Q.N., Pham, P.K. and Wei, S.X. (2011). Large foreign ownership and firm-level stock return volatility in emerging markets. Journal of Financial and Quantitative Analysis, 46(4), pp.1127-1155.

[14] Li, B., Rajgopal, S. and Venkatachalam, M. (2014). R2 and idiosyncratic risk are not interchangeable. The Accounting Review, 89(6), pp.2261-2295.

[15] Schuppli, M. and Bohl, M.T. (2010). Do foreign institutional investors destabilize China's A-share markets? Journal of International Financial Markets, Institutions and Money, 20(1), pp.36-50.

[16] Stiglitz, J.E. (2000). Capital market liberalization, economic growth, and instability. World development, 28(6), pp.1075-1086. 
[17] Stiglitz, J.E. (2010). "Risk and Global Economic Architecture: Why Full Financial Integration May Be Undesirable." American Economic Review 100.2(2010):388-392.

[18] Kaminsky, G. L. and Reinhart, C. M. (1999). "The Twin Crises: The Causes of Banking and Balance-of-Payments Problems." American Economic Review 89.3(1999):473-500.

[19] Umutlu, M., Akdeniz, L. and Altay-Salih, A. (2010). The degree of financial liberalization and aggregated stock-return volatility in emerging markets. Journal of banking \& finance, 34(3), pp.509-521. 